\title{
The cost of inequality
}

\author{
Deciding on an equitable, inclusive, sustainable development path globally, instead of business as usual, is the only \\ way out of the current crises and to avert future crises.
}

A lthough almost two years have passed since the coronavirus outbreak took hold of the world, many nations are still grappling today with waves of infections, restrictions to people's movement, vaccine resistance and the socioeconomic consequences of the pandemic-related disruptions. A lot has been said about how countries managed, or mismanaged, this intertwined public health and economic crisis. However, amid conflicting views and misinformation, government U-turns and muddled decisions, it soon became clear how hard it would be for many countries across the Global South to respond promptly and robustly to rising infections. The inequality of means between the Global North and the Global South has cost way too many lives so far. And if that wasn't enough, when the response has been overly slow or insufficient, the socioeconomic impacts of the pandemic have been much more acute than necessary, pushing many more into deeper poverty and so jeopardizing the prospects of future generations ${ }^{1}$.

On 7 February, the Commission for Social Development of the Economic and Social Council of the United Nations began their 60th session calling for countries to strengthen social protection as a matter of priority to ensure an inclusive recovery ${ }^{2}$. The COVID-19 pandemic has amplified all those inequalities that governments and multilateral organizations had been prioritizing through various programmes and initiatives, including the Sustainable Development Goals agenda more recently, and has also brought to light the fragility of socioeconomic systems across more advanced countries.

Against this backdrop, the need for systemic change feels more urgent than ever, as unanimously advocated by many from across academia, civil society, government and even the private sector. Indeed, the 2022-2025 strategic plan of the United Nations Development Programme ${ }^{3}$ explicitly states its aim to support countries to go beyond short-term development challenges and to achieve systemic change. The strategic plan includes six areas of focus for action, named 'signature solutions', which include inequality and the environment.

Tackling inequalities as an integral dimension of sustainable development is a central theme at Nature Sustainability. We are interested in contributions that shed light

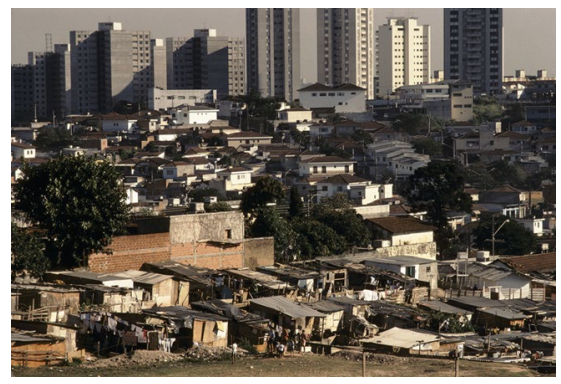

Credit: Mike Goldwater / Alamy Stock Photo

on how to build a development path that levels up access to opportunities across all societal groups of all countries, that ensures that human well-being is maintained now and in the future through a responsible, frugal management of natural resources, and that takes a long-term perspective. We certainly share the views of many experts and practitioners that in order to advance on such a development path, systemic change is needed. Our vision is ultimately one of changing the way people interact with nature, and through this lens we look at inequalities and development more broadly.

In this issue of Nature Sustainability, we feature a Perspective article by Rao and Wilson proposing an integrated and interdisciplinary research framework that ties energy use and well-being to consumption through lifestyles. The proposed framework aims to assess both the human and resource impacts of changing societies and of policy interventions intended to shape behaviour. The authors discuss, for example, how a low energy-demand future that benefits both development and the climate (our peoplenature interface) hinges on a fundamental shift from individualist lifestyles to a sharing economy - some sort of systemic change, one could argue. Achieving such a change requires, among other things, a full understanding of the well-being implications of a shared use of collective resources. The authors also point out the need to integrate social science research that addresses issues such as the disproportionate burden of fossil fuel extraction borne by Indigenous people and people of colour across the world (going back to inequalities) with research on climate change and energy use.

Hopefully, articles such as the one by Rao and Wilson will stimulate reflections by bringing together diverse experts, research traditions and perspectives about the kinds of research questions and frameworks that will more likely contribute knowledge to inform sustainable development decisions - decisions that can trigger change and, even better, systemic change. We at Nature Sustainability are of the view that more integration efforts are needed.

But research efforts such as the one proposed above require commitment, resources and time for dialogue. Some would say that time for change and time for building new alliances and new collaborations is running out. We only need to look at how fast the impacts of the ongoing pandemic, climate change and ecological collapse are unfolding to feel the urgency. It's true, we need to act fast faster than we have done until now; and we have said this before ${ }^{4}$ and more than once, sometimes not without a sense of frustration. But this time we want to end our thoughts here with optimism. We are confident that scholars, practitioners, and citizens will contribute to change; indeed, it is already happening. We also feel that governments and private sector leaders can change priorities and make decisions in line with more equitable, inclusive, sustainable development paths. The pandemic, the climate crisis and biodiversity loss dominate national, regional and international debates, and decision-makers are responding, not without flaws, of course, but they are engaging - the true cost of inequalities and their human-nature complexities are at present so palpable that shying away from them is not an option anymore.

Nature Sustainability will keep playing its part with commitment and enthusiasm disseminating the best ideas and knowledge for the betterment of life on planet Earth. $\square$

Published online: 23 February 2022 https://doi.org/10.1038/s41893-022-00860-5

\footnotetext{
References

1. Narayan, A. et al. COVID-19 and Economic Inequality: Short-Term Impacts with Long-Term Consequences Policy Research Working Paper, No. 9902 (World Bank, 2022); https://go.nature. $\mathrm{com} / 33 \mathrm{haOVg}$

2. Commission for Social Development. Opening Remarks by H.E. Collen Vixen Kelapile, President of the Economic and Social Council (ECOSOC) (ECOSOC, 7 February 2022); https:// go.nature.com $/ 3 \mathrm{HQIAzN}$

3. Strategic Plan 2022-2025 (United Nations Development Programme, 2021); https://go.nature.com/3srh7hi

4. Nat. Sustain. 4, 831 (2021)
} 